\title{
Colorimetric Disposable Paper Coated with ZnO@ZnS Core-Shell Nanoparticles for Detection of Copper Ions in Aqueous Solutions
}

\author{
Azar Sadollah Khani, Amir Hatamie, Omer Nur, Magnus Willander, Behrooz Zargar and Iraj \\ Kazeminezhad
}

\section{Linköping University Post Print}

\section{Tweet}

N.B.: When citing this work, cite the original article.

Original Publication:

Azar Sadollah Khani, Amir Hatamie, Omer Nur, Magnus Willander, Behrooz Zargar and Iraj Kazeminezhad, Colorimetric Disposable Paper Coated with ZnO@ZnS Core-Shell Nanoparticles for Detection of Copper Ions in Aqueous Solutions, 2014, ACS Applied Materials and Interfaces, (6), 20, 17694-17701.

http://dx.doi.org/10.1021/am505480y

Copyright: American Chemical Society http://pubs.acs.org/

Postprint available at: Linköping University Electronic Press http://urn.kb.se/resolve?urn=urn:nbn:se:liu:diva-112477 


\section{Colorimetric Disposable Paper Coated with ZnO@ZnS Core-shell Nanoparticles for Detection of Copper Ions in Aqueous Solutions}

Azar Sadollahkhani $^{\mathrm{ac} *}$, Amir Hatamie ${ }^{\mathrm{ab}}$, Omer Nur $^{\mathrm{a}}$, Magnus Willander ${ }^{\mathrm{a}}$

${ }^{a}$ Department of Science and Technology, Campus Norrköping, Linköping University, SE-60174 Norrköping, Sweden

Behrooz Zargar ${ }^{\mathrm{b}}$

${ }^{\mathrm{b}}$ Department of Chemistry, Faculty of Sciences, Shahid Chamran University, Ahvaz, Iran

Iraj Kazeminezhad ${ }^{\mathrm{c}}$

${ }^{c}$ Nanotechnology Lab., Department of Physics, Shahid Chamran University, Ahvaz, Iran

*Corresponding author: Azar Sadollahkhani Email: azar.sadollah.khani@liu.se;

azarkhanny@gmail.com

\section{Abstract}

In this study we have proposed a new nanoparticle-containing test paper sensor that could be used as an inexpensive, easy-to-use, portable, and highly selective sensor to detect $\mathrm{Cu}^{2+}$ ions in aqueous solutions. This disposable paper sensor is based on $\mathrm{ZnO} @ \mathrm{ZnS}$ core shell nanoparticles. The core shell nanoparticles were synthesized using a chemical method and then they were used for coating the paper. The synthesis of the $\mathrm{ZnO} @ \mathrm{ZnS}$ core shell nanoparticles was performed at a temperature as low as 60 ${ }^{\circ} \mathrm{C}$, and so far this is the lowest temperature for the synthesis of such core shell nanoparticles. The sensitivity of the paper sensor was investigated for different $\mathrm{Cu}^{2+}$ ion concentrations in aqueous solutions and the results show a direct linear relation between the $\mathrm{Cu}^{2+}$ ions concentration and the colour intensity of the paper sensor with a visual detection limit as low as $15 \mu \mathrm{M}(\sim 0.96 \mathrm{ppm})$. Testing the present paper sensor on real river turbulent water shows a maximum $5 \%$ relative error for determining the $\mathrm{Cu}^{2+}$ ions concentration which confirms that the presented paper sensor can successfully be used efficiently for detection in complex solutions with high selectivity. Photographs of the paper sensor taken using a regular digital camera were transferred to a computer and analysed by ImageJ Photoshop software. This finding demonstrates the potential of the present disposable paper sensor for the development of a portable accurate and selective heavy metal detection technology.

Key words: Colorimetric detection, Copper ion, Core shell nanoparticles, ImageJ software, 


\section{Introduction}

In recent years, the sensing and recognition of cations and anions has emerged as a key research field within chemistry because of the important role of cations and anions in a wide range of industrial, environmental problems, and for biological systems. ${ }^{1,2}$ Therefore, the recognition and sensing of the cationic and anionic analysts has attracted considerable attention as a significant goal of research programs. ${ }^{3-5}$ Among the different methods for sensing cationic and anionic analysts, colorimetric sensors have attracted more attention, due to their simplicity, rapidity, precision and common availability of the basic equipment in laboratory and field research. ${ }^{6-11}$ Furthermore, colorimetric methods are extremely attractive in the field of detection, because the read out is easy. It can be performed using the naked eye, offering advantages of simplicity and rapidity, along with the additional benefits of cost-effectiveness and no requirement of any sophisticated instrumentation. ${ }^{12,13}$ Recently, paper based analytical devices have gained great interest due to their attractive advantages, such as low cost and simplicity. Compared to the conventional analytical methods that require complex instrumentation, paper based analytical devices are usually integrated with simple colorimetric detection systems. ${ }^{7,8}$

Heavy metal ions such as $\mathrm{Cu}^{2+}, \mathrm{Zn}^{2+}, \mathrm{Cd}^{2+}$, and $\mathrm{Hg}^{2+}$ represent a threat to human health and the whole environment and for this reason they have attracted a lot of attention in different research fields. ${ }^{14}$ Copper, the third most abundant transition metal ions in the human body, plays an important role in a variety of fundamental biological processes in organisms and acts as an essential trace element. Nevertheless, Copper with high concentrations can induce toxic effects in living organisms and cause severe diverse effects in humans. For instance, excess copper in drinking water has been suspected of causing liver cirrhosis in children, and has been linked to serious neurodegenerative diseases. ${ }^{15-17}$ Therefore excess amount of copper can threaten human health, and hence copper removal from drinking water is an important issue which must be considered. For this purpose, the first step is 
the detection and the accurate quantification of $\mathrm{Cu}^{2+}$ ions in drinking water. Although some studies have been conducted in this area and some methods have been demonstrated for the detection of the $\mathrm{Cu}^{2+}$ ions in the water, ${ }^{18-21}$ there is still a lack of a portable, disposable, highly sensitive and selective and easy-to-use sensor based on colorimetric response which is usable with naked eyes. Such disposable detection method will be useful for the public and especially in remote areas were drinking water is supplied from local wells and small running streams.

Nowadays, nanomaterials have attracted extensive interest in modern chemistry due to their unique superior properties for optical, electronic, magnetic, and catalytic effects. Among the different nanomaterials, zinc oxide nanoparticles (ZnO NPs) have their own importance due to their vast area of applications, such as: chemical and bio-sensing, cosmetics, optical and electrical devices, drugdelivery, and solar cells etc. ${ }^{22,23}$ Also, covering ZnO NPs with another material can tune its properties to make it useful in other research area ${ }^{24}$. Nowadays, considerable effort has been devoted to the design and fabrication control of ZnO@ZnS CSNPs. Various ZnO@ZnS core-shell nanostructures have been synthesized, most of them at elevated temperature. ${ }^{25}$ Epitaxial growth of $\mathrm{ZnS}$ shell on $\mathrm{ZnO}$ core is obtained by the high-temperature synthesis. In contrast, low-temperature synthesis with low cost can lead to a uniform nanocrystalline $\mathrm{ZnS}$ structure, but so far only a limited number of publications can be found. ${ }^{26}$ There is a lack of simple and fast reliable way for the growth of pure $\mathrm{ZnO} @ \mathrm{ZnS}$ CSNPs with full coverage of the shell material. In the work reported by Nam et al ${ }^{27}$ the starting materials and the method are different from the present manuscript, and the grown ZnO@ZnS CSNPs are quite larger in size (more than $200 \mathrm{~nm}$ ) compared to the core shell nanoparticles presented in this work. Sharma et al ${ }^{28}$ the reported a preparation method of the $\mathrm{ZnO} @ \mathrm{ZnS}$ CSNPs using the same precursors as ours, while their HRTEM results show a non-uniform core/shell NPs. Liu et al successfully obtained a full coverage of $\mathrm{ZnS}$ shell at low temperature, but with a more time consuming process than presented herein. ${ }^{29}$ Recently Wenjiang et. al reported the synthesis of ZnS@ZnO CSNPs 
using the hydrothermal chemical growth using a temperature as high as $160{ }^{\circ} \mathrm{C} .{ }^{30}$ For utilizing $\mathrm{ZnO} @ \mathrm{ZnS}$ CSNPs on any type of soft substrate, it would be of interest to reduce the synthesis temperature much below $160^{\circ} \mathrm{C}$.

In this research paper, we have fabricated an easy-to-use, highly selective and sensitive test paper based on $\mathrm{ZnO} @ \mathrm{ZnS}$ core shell nanoparticles (CSNPs) synthesized using the chemical approach at a temperature as low as $60{ }^{\circ} \mathrm{C}$. This low temperature synthesis is, as far as we know, the lowest temperature reported for the synthesis of such CSNPs. The developed paper sensor can detect $\mathrm{Cu}^{2+}$ in aqueous solutions. The demonstrated paper sensor indicates the potential application for detecting $\mathrm{Cu}^{2+}$ in the aqueous environmental samples e.g. fresh drinking water without any spectroscopic instrumentation. The colour intensity of the paper sensor can be monitored by the naked eyes. The pictures of the test papers were taken with a regular digital camera and transferred to the computer and analysed by ImageJ Photoshop software. An observed direct linear relation between the colour intensity and the $\mathrm{Cu}^{2+}$ concentration shows that increase of the $\mathrm{Cu}^{2+}$ concentration in the solution leads to enhancement of the colour intensity. Eventually, in order to indicate the superiority of using $\mathrm{ZnO} @ \mathrm{ZnS}$ CSNPs, the utility of using ZnO nanoparticles (NPs) was investigated and compared to the CSNPs. It was found that pure $\mathrm{ZnS}$ NPs do not disperse uniformly in aqueous water solutions as compared to the ZnO@ZnS CSNPs and subsequently cannot create a uniform spot on the paper sensor.

\section{Experimental}

\subsection{Chemicals and Materials}

Zinc acetate dehydrates $\left(\mathrm{ZnAC}_{2} .2 \mathrm{H}_{2} \mathrm{O}\right)$ and sodium hydroxide $(\mathrm{NaOH})$ were used as the starting materials for preparing the $\mathrm{ZnO} \mathrm{NPs}$ and sodium sulfide $\left(\mathrm{Na}_{2} \mathrm{~S}\right)$, zinc chloride $\left(\mathrm{ZnCl}_{2}\right)$ and isopropanol were used as precursors for covering the $\mathrm{ZnO}$ NPs with $\mathrm{ZnS}$. Copper nitrate trihydrate was used to prepared different solution with various $\mathrm{Cu}^{2+}$ concentrations to study the colorimetric responses of the 
paper sensor. All chemicals were of analytical grade and were purchased from Sigma Aldrich. Filter paper with $0.22 \mu \mathrm{m}$ pore size was purchased from Millipore for making the paper sensors.

\subsection{Instruments}

The structural characteristics of the ZnO@ZnS CSNP and the paper sensor were investigated by X-ray powder diffraction (XRD) using a Phillips PW 1729 powder diffractometer equipped with CuK $\alpha$ radiation $(\lambda=1.5418 \AA$ ) operating at a generator voltage of $40 \mathrm{kV}$ and a current of $40 \mathrm{~mA}$. The high resolution transmission electron microscopy (HRTEM) characterization was carried out using a FEI Tecnai G2 TF20 UT instrument with a field-emission gun operated at $200 \mathrm{kV}$. The instrument has a point resolution of $0.19 \mathrm{~nm}$ and is equipped with an EDX system. The TEM specimen was prepared by dispersing the nanostructure powder on a copper grid with a thin amorphous carbon film. Photographic results were recorded using a 13 Megapixel camera of the Galaxy Note III and were analyzed with a ImageJ software.

\subsection{Synthesize of ZnO NPs and ZnO@ZnS CSNPs}

In order to grow $\mathrm{ZnO} \mathrm{NPs}$, zinc acetate dehydrate and sodium hydroxide were dissolved in deionized water to form two transparent solutions with $0.5 \mathrm{M}$ and $1 \mathrm{M}$ concentrations respectively, and then, they were added drop-wise into a beaker at room temperature. After 2 hours of stirring, the obtained precipitation was separated by centrifugation. Finally the precipitation was washed with deionized water and acetone and was dried at $75^{\circ} \mathrm{C}$. Covering the $\mathrm{ZnO}$ NPs with the $\mathrm{ZnS}$ was performed by adding $0.30 \mathrm{~g}$ of the as-grown $\mathrm{ZnO} \mathrm{NPs}$ to $50 \mathrm{ml}$ isopropanol and sonication for 10 minutes. After adjusting the $\mathrm{pH}$ at 10 a solution of $\mathrm{Na}_{2} \mathrm{~S}$ was added to the mixture drop-wise. The solution was stirred for 2 hours at $60^{\circ} \mathrm{C}$, and then a solution of $0.05 \mathrm{M} \mathrm{ZnCl}_{2}$ was added drop-wise into the above mixture and stirred for 1 hour. Afterwards, the product was washed with deionized water and acetone and dried at $70^{\circ} \mathrm{C}$. 


\subsection{Preparation of paper sensor}

In order to prepare the sensor for the detection of $\mathrm{Cu}^{2+}$ ions, a uniform and soft surface which is fully covered with the $\mathrm{ZnO} @ \mathrm{ZnS}$ CSNPs is needed. Using a relatively large amount of $\mathrm{ZnO} @ \mathrm{ZnS}$ CSNPs can lead to form large and non-uniform surface which usually results in non-concentrated color intensity from the samples under investigation and this causes some difficulties for analyzing the data. In order to make the paper sensor, a $0.5 \%(\mathrm{~W} / \mathrm{V})$ solution of the as-grown $\mathrm{ZnO} @ \mathrm{ZnS}$ CSNPs was prepared. The uniform solution was obtained after 5 min ultra-sonication and 30 min stirring alternatively. Then $10 \mu \mathrm{L}$ of the mentioned solution was dropped on a piece of paper and was kept in the room temperature for $30 \mathrm{~min}$ to dry. Then different solutions with various $\mathrm{Cu}^{2+}$ concentrations (15 $\mu \mathrm{M}, 75 \mu \mathrm{M}, 150 \mu \mathrm{M}, 300 \mu \mathrm{M}, 450 \mu \mathrm{M}, 750 \mu \mathrm{M}$, and $1500 \mu \mathrm{M})$, were prepared to investigate the colorimetric responses of the paper sensor. All the experimental solutions were prepared using deionized water (18 $\mathrm{M} \Omega$ resistivity) and for testing the paper sensor in a complex solution, $\mathrm{C} \mathrm{Cu}^{2+}$ solution with three different concentrations was prepared using turbulent real water from Motala Stream River in Norrkoping city, Sweden. The samples were photographed by a 13 Megapixel camera of the Galaxy Note III with auto mode. In order to measure the color intensity of the images, the pictures were transferred to a computer and analyzed by ImageJ Photoshop software. The analysis was carried out based on the color intensity of each picture. This program has the ability of measuring the color intensity at a specific region with desired size. So the same region of each spot (centre of the spot) with the same size $(36 \times 36$ pixels $)$ was analyzed to determine the color intensity. The choice of the region from the center was adopted to avoid edges of the circle which have a different concentration compared to the center. The output results obtained from the ImageJ software are collected in two different forms. One shows the color intensity qualitatively, and also the software give us another outputs such as color intensity value, which is a number to show the color intensity quantitatively. It is important here to mention that the 
value of the intensity collected by the Camera depends on the lighting intensity in the medium of measurement. Nevertheless, the software can be calibrated to consider the medium condition(s) to provide real adjusted values.

\section{Results and discussion}

\subsection{Characterization of the ZnO@ZnS CSNPs}

The XRD pattern of the ZnO@ZnS CSNPs is shown in Figure 1a. As it is clear the peaks of the $\mathrm{ZnO} \mathrm{NPs}$ can be indexed to the known hexagonal wurtzite structure with lattice constants of $\mathrm{a}=\mathrm{b}=3.250 \AA$ and $\mathrm{c}=5.207 \AA$ (JCPDF: 79-2205). Furthermore, a wide peak at $29^{\circ}$ belongs to the $\mathrm{ZnS}$ (JCPDF: 50566) indicating the coverage the ZnO NPs with ZnS. EDX mapping when using the HRTEM was performed to confirm that the $\mathrm{ZnO}$ core structure is fully covered by a $\mathrm{ZnS}$ shell and is shown in Figure $1 \mathrm{~b}$. The distribution of sulfur, oxygen, and zinc confirms that the $\mathrm{ZnO}$ as a core is completely surrounded by the $\mathrm{ZnS}$ as a shell. Further information about the surface of $\mathrm{ZnO} @ \mathrm{ZnS}$ CSNPs was found using ATR-FTIR. As it can be seen from Figure 1c, the peak at around $1100 \mathrm{~cm}^{-1}$ is the $\mathrm{ZnS}$ vibration peak and exhibits that the $\mathrm{ZnO}$ nanoparticles is capped with $\mathrm{ZnS}$. Moreover, the peak which is observed from $400 \mathrm{~cm}^{-1}$ to $500 \mathrm{~cm}^{-1}$ is due to $\mathrm{Zn}-\mathrm{O}$ vibrations of $\mathrm{ZnO}$ NPs. SEM image was prepared to investigate the morphology and the uniformity of the $\mathrm{ZnO} @ \mathrm{ZnS}$ CSNPs and is shown in Figure 1d.

\subsection{Colorimetric measurements}

Since the aim of this work was to demonstrate a portable and easy-to-use paper sensor for the detection of $\mathrm{Cu}^{2+}$ ions in drinking water, the steady state reaction time between $\mathrm{Cu}^{2+}$ and the paper sensor must be determined. Moreover, as the $\mathrm{pH}$ is an important parameter in redox reactions it is important to determine the optimum $\mathrm{pH}$ for the operation of the paper sensor, and the buffer 
concentration of the $\mathrm{Cu}^{2+}$ solution. Then before exploring the sensing activity of the paper sensor, the steady state time, effect of $\mathrm{pH}$, and the effect of buffer concentration were investigated.

\subsubsection{Colour development time}

In order to investigate the effect of time on the colorimetric response of the paper sensor, a 1 $\mathrm{mM}$ solution of the $\mathrm{Cu}^{2+}$ was prepared and $20 \mu \mathrm{L}$ of this solution was dropped on the paper sensor. Then the paper sensor was photographed over 30 min with images recorded every 5 min. Figure $2 \mathrm{a}$ indicates the column plot of the colour intensity versus time and Figure $2 b$ shows the real image of the paper sensor for each time. According to this Figure, after $20 \mathrm{~min}$ the changes in colour intensity reaches a steady value and we can consider it as a steady state reaction time and in the subsequence experiments all the pictures are taken after $20 \mathrm{~min}$.

\subsubsection{Effect of the pH on the operation of the paper sensor}

In order to specify the optimum $\mathrm{pH}$ for the performance of the sensor in the $\mathrm{Cu}^{2+}$ solution i.e. the optimum colorimetric response of the paper sensor, a solution with $1 \mathrm{mM} \mathrm{Cu}{ }^{2+}$ concentration was prepared with three different $\mathrm{pH}$ values of 4,7 , and 11 . Then a $10 \mu \mathrm{L}$ of each solution was drop-casted on the paper sensor and dried at room temperature. After $20 \mathrm{~min}$, the samples were photographed and the results were analysed by the ImageJ Photoshop software to determine the colour intensity of the paper sensor for each of the three different $\mathrm{pH}$ values. Figure $3 \mathrm{a}$ shows the column plot of the colour intensity versus $\mathrm{pH}$ of the $\mathrm{Cu}^{2+}$ solution with the picture of each sample as an inset. It was observed that, at $\mathrm{pH} 11$, the $\mathrm{Cu}^{2+}$ ions started to sediment (to form $\mathrm{Cu}(\mathrm{OH})_{2}$ ) and do not participate in the reaction, so the exact amount of the $\mathrm{Cu}^{2+}$ ions could not be detected at this $\mathrm{pH}$ value. As it is well known the $\mathrm{pH}$ value of most environmental samples is around 7 but according to our results shown in Figure 3a the best efficiency of the present paper sensor (strongest color intensity) was obtained at $\mathrm{pH}$ 
4 which shows that the reaction between the $\mathrm{Cu}^{2+}$ ions and the paper sensor is more severe at this $\mathrm{pH}$, therefore a $\mathrm{pH}$ value of 4 was selected as an optimum operating $\mathrm{pH}$ for further experiments.

\subsubsection{Effect of buffer concentration}

Different buffer concentrations were obtained by preparing $1 \mathrm{mM} \mathrm{Cu}^{2+}$ solution at $\mathrm{pH} 4$ with different buffer concentrations (10 mM, $15 \mathrm{mM}, 20 \mathrm{mM}$, and $25 \mathrm{mM})$. Figure $3 \mathrm{~b}$ indicates the column plot of colour intensity for different buffer concentrations with the image of each sample as an inset. Image analysis shows that, the detected $\mathrm{Cu}^{2+}$ in the solution with $10 \mathrm{mM}$ buffer concentration indicates the highest intensity compared to the other concentrations and can be considered as a preferable buffer concentration.

\subsection{Detection of $\mathrm{Cu}^{2+}$ on the paper sensor}

All the above results show that for getting the best response from the paper sensor the $\mathrm{pH}$ and buffer concentration of the $\mathrm{Cu}^{2+}$ solution must be adjusted at 4 and $10 \mathrm{mM}$ respectively and the samples should be photographed after $20 \mathrm{~min}$.

In order to determine the response of the paper sensor for detecting the $\mathrm{Cu}^{2+}$ in the aqueous solutions with different concentrations, six different solutions with various concentration of the $\mathrm{Cu}^{2+}$ (15 $\mu \mathrm{M}, 75 \mu \mathrm{M}, 150 \mu \mathrm{M}, 300 \mu \mathrm{M}, 450 \mu \mathrm{M}, 750 \mu \mathrm{M}$, and $1500 \mu \mathrm{M})$ were prepared. As it was mentioned above, the $\mathrm{pH}$ and the buffer concentration of each solution were adjusted at 4 and $10 \mathrm{mM}$, respectively. $20 \mu \mathrm{L}$ of each solution was drop-casted on the piece of the paper sensor and after 20 min a photograph was taken using the digital camera. Figure $4 \mathrm{a}$ shows the color intensity versus the $\mathrm{Cu}^{2+}$ ions concentration obtained by the Image $\mathrm{J}$ with a digital photograph shown as an inset. While in Figure $4 \mathrm{~b}$ indicates the value of the color intensity versus the $\mathrm{Cu}^{2+}$ ions concentration. The insert of Figure $4 \mathrm{~b}$ shows a digital photograph of the paper sensor. Figure $4 \mathrm{c}$ shows the calibration curve of the color intensity at different concentrations of the $\mathrm{Cu}^{2+}$ ions. According to Figure $4 \mathrm{c}$, the as-prepared paper 
sensor response to variations of the $\mathrm{Cu}^{2+}$ ions concentration is observed to be linear. As shown, when decreasing the concentration of the $\mathrm{Cu}^{2+}$ ions in the solution a decrease of the color intensity was observed as expected. The linearity of the calibration curve confirms the ability of this paper sensor to measure the concentration of the $\mathrm{Cu}^{2+}$ ions in different solutions. Also, the relative standard deviation was calculated to be $7.1 \%$ for the determination of $1000 \mu \mathrm{M} \mathrm{Cu}^{2+}$ and this shows that the sensor has an acceptable precision.

The detection limit of this sensor was found to be about $15 \mu \mathrm{M}$ which is lower than the critical standard level of $\mathrm{Cu}^{2+}$ allowed in drinking water (WHO standard: $30 \mu \mathrm{M}$; EPA and China standard:20 $\mu \mathrm{M}) .{ }^{19,31,32}$ Table 1 displays a comparison between the results of the present method and some other reported methods. As it can be seen, by applying a simple and fast technique to analyze the data as in this study, we have obtained an acceptable detection limit.

\subsection{Paper sensor respond to another cations and anions}

To investigate the practical application, i.e. the selectivity of the paper sensor, it was utilized to sense various cations and anions $\left(\mathrm{Na}^{+}, \mathrm{K}^{+}, \mathrm{Mg}^{2+}, \mathrm{Co}^{2+}, \mathrm{Ca}^{2+}, \mathrm{Ni}^{2+}, \mathrm{Al}^{3+}, \mathrm{Si}^{4+}, \mathrm{Fe}^{2+}, \mathrm{Fe}^{3+}, \mathrm{Cd}^{2+}, \mathrm{Cl}^{-}, \mathrm{NO}_{3}^{-}\right.$ , and $\mathrm{CO}_{3}{ }^{2-}$ ). A solution with $1.5 \mathrm{mM}$ concentration of each of these cations and anions was prepared at pH 4 with $10 \mathrm{mM}$ of the buffer solution concentration. Then a $20 \mu \mathrm{L}$ of each solution was dropped on the paper sensor and dried at room temperature. The pictures were taken after $20 \mathrm{~min}$ and are shown in Figure 5. As it is clear, although the sensor responds to the $\mathrm{Fe}^{2+}, \mathrm{Fe}^{3+}$ ions but the obvious colour change takes place only by adding $\mathrm{Cu}^{2+}$ ions. Therefore, this paper sensor could directly detect $\mathrm{Cu}^{2+}$ ions in the aqueous solutions without a negative effect from other cations and anions that could be available in the aqueous solution. Hence the present paper sensor possesses a high selectivity for $\mathrm{Cu}^{2+}$ ions. 
The other disturbing factor which needs to be considered is Humic substances. But as it is known, the concentration of these compounds is not too high in aqueous samples so the amount of water which has been dropped on to the sensor is not enough for these compounds to be enriched onto the present paper sensor. ${ }^{37,38}$

\subsection{Analysis of the real sample}

In order to investigate the ability of this paper sensor to perform in a solution with different unknown pollutant, the water of the Motala stream river (Norrköping, Sweden) was used as a complex solution. Before preparing the solution, water was tested with the paper sensor and no $\mathrm{Cu}^{2+}$ ions were found in the water. Then three solutions with different $\mathrm{Cu}^{2+}$ concentrations $(1.5 \mathrm{mM}, 300 \mu \mathrm{M}$, and 75 $\mu \mathrm{M})$ were prepared and the $\mathrm{pH}$ and buffer concentration of them were adjusted at 4 and $10 \mathrm{mM}$ respectively. A $20 \mu \mathrm{L}$ of each solution was dropped on the paper sensor and dried at room temperature. The paper sensor was photographed and the pictures were transferred to the computer to calculate the colour intensity and measuring the equivalent $\mathrm{Cu}^{2+}$ concentration using calibration curve. In order to compare the color intensity of the real samples to that of the experimental samples which was prepared

using deionized water, the column plot of color intensity is shown in Figure 6. Table 2 shows the measured $\mathrm{Cu}^{2+}$ concentration of each solution using this method and also the relative error of each one. This amount of relative error is acceptable and confirms the practical applicability of this paper sensor to detect $\mathrm{Cu}^{2+}$ ions in complicated solutions.

\subsection{Comparing the performance of $\mathrm{ZnS}$ NPs and $\mathrm{ZnO} @ \mathrm{ZnS}$ CSNPs as a $\mathrm{Cu}^{2+}$ detection sensor}

ZnS NPs were synthesized using a co-precipitation method. ${ }^{39}$ Then the ability of bare $\mathrm{ZnS}$ nanoparticles instead of ZnO@ZnS CSNPs was studied by preparing the same paper sensor using ZnS NPs. In order to prepare a uniform 0.5 M ZnS solution, the mixture was stirred for 24 hrs, after 30 min exposing to the ultrasonic wave. It was observed that the $\mathrm{ZnS}$ NPs has limited dispersibility in water 
compare to the ZnO@ZnS CSNPs which can be dispersed in water after ultrasonication for 5 min and 30 min stirring. $10 \mu \mathrm{L}$ of the as-prepared $\mathrm{ZnS}$ solution was placed on the piece of the paper and dried at room temperature. The sensing activity of the ZnS NPs paper sensor was examined by dropping $20 \mu \mathrm{L}$ of different solutions with various $\mathrm{Cu}^{2+}$ concentrations. Figure 7 shows the colorimetric response of the paper sensor for different concentration of the $\mathrm{Cu}^{2+}$ ions. Since it was not possible to obtain a uniform $\mathrm{ZnS}$ solution, the colorimetric response behaviour of this paper sensor was not uniform or repeatable. This result show that using a paper sensor coated with ZnO@ZnS CSNPs not only indicates a uniform spot under influence of $\mathrm{Cu}^{2+}$ ions, but is easy to be prepared because of its uniform dispersibility in water.

\section{The mechanism of $\mathrm{Cu}^{2+}$ detection sensor}

Once the $\mathrm{Cu}^{2+}$ was transferred on to the sensor, cation exchange begins at the interface between the ZnO@ZnS CSNPs surface and the $\mathrm{Cu}^{2+}$ aqueous solution. The driving force for the cation exchange is provided by the large difference in solubility between the $\mathrm{ZnS}$, and the $\mathrm{CuS}$, [solubility product constant $\left(\mathrm{K}_{\mathrm{sp}}\right)$ of $\mathrm{ZnS}$ is $2.93 \times 10^{-25}$ and $\mathrm{K}_{\mathrm{sp}}$ for $\mathrm{CuS}$ is $\left.8 \times 10^{-37}\right] .{ }^{40,41}$ In order to investigate the mechanism of the present paper sensor for detecting $\mathrm{Cu}^{2+}$ ions in aqueous solutions, the $\mathrm{XRD}$ spectra of the paper and the paper sensor after and before the addition of the $\mathrm{Cu}^{2+}$ ions were measured. According to Figure 8, after the addition of the $\mathrm{Cu}^{2+}$ on the paper sensor two additional peaks appeared. A comparison with the standard card (JCPDF: 006-0464) the peak around $27.6^{\circ}$ belongs to the CuS crystal plane of (101). Also a careful perusal of XRD image shows that the intensity of the peak at $32^{\circ}$ became higher by adding $\mathrm{Cu}^{2+}$ ions. Since the $\mathrm{CuS}$ has a peak at this angle that belongs to the (101) crystal plane, we can claim that the reaction between the paper sensor and the $\mathrm{Cu}^{2+}$ leads to the formation of $\mathrm{CuS}$ and color changing from white to brown confirms this fact. ${ }^{42}$ We postulate that the following reaction takes place and the cation in the shell of CSNPs (i.e. the $\mathrm{Zn}^{2+}$ ) was simply exchanged with the $\mathrm{Cu}^{2+}$ ions according to the following reaction: 


$$
\mathrm{ZnS}_{(S)}+\mathrm{Cu}_{(a q)}^{2+} \rightarrow \mathrm{CuS}_{(S)}+\mathrm{Zn}^{2+}{ }_{(a q)}
$$

Also, according to the SEM images of the paper (without adding nanoparticles), the paper (after adding nanoparticles) and the used paper (after adding $\mathrm{Cu}^{2+}$ ions) shown in Figure 9, adding the $\mathrm{Cu}^{2+}$ ions leads to increase the agglomeration. Increasing the agglomeration could be explained by considering the fact that, as the $\mathrm{ZnO} @ \mathrm{ZnS} \mathrm{CSNP}$ are accumulated on the paper, by adding the $\mathrm{Cu}^{2+}$ to the paper the $\mathrm{Cu}^{2+}$ ions will react with a cluster of $\mathrm{ZnO} @ \mathrm{ZnS}$ CSNPs and this can further increase the size and agglomeration.

\section{Conclusions}

In this study a portable, highly sensitive and selective and easy-to - use paper sensor for detecting $\mathrm{Cu}^{2+}$ ions in aqueous solution was prepared using ZnO@ZnS CSNPs. The ZnO@ZnS CSNPs were synthesized using a low temperature chemical method which is fast and easy to use. The grown CSNPs were coated on a paper and were utilized as a disposable paper sensor. The optimum $\mathrm{pH}$ and buffer concentration of the $\mathrm{Cu}^{2+}$ solution presented here were obtained as 4 and $10 \mathrm{mM}$, respectively. In order to investigate the sensing activity, the paper sensor was tested in presence of different concentration of the $\mathrm{Cu}^{2+}$. The paper sensor was photographed and the results were analysed using ImageJ software. The results show that increasing the $\mathrm{Cu}^{2+}$ concentration leads to linear increase of the colour intensity of the paper sensor. Testing the paper sensor in a complex turbulent solution confirmed the practical applicability of the presented disposable paper sensor. The lower limit of detection estimated from the present sensor was $15 \mu \mathrm{M}(\sim 0.96 \mathrm{ppm})$, which is less than the international allowed level of $\mathrm{Cu}^{2+}$ ions in drinking water. The findings and use of CSNPs presented here indicate the potential as the method adopted is a low cost, easy and can be scaled up for mass production. 


\section{Acknowledgment}

The authors would like to thank Shahid Chamran University and Linkoping Universityfor financial support.

\section{References:}

(1) Cha, R.; Wang, D.; He, Z.; Ni, Y. Development of Cellulose Paper Testing Strips for Quick Measurement of Glucose Using Chromogen Agent. Carbohydr. Polym. 2012, 88, 1414- 1419.

(2) Zargar, B.; Hatamie, A. Localized Surface Plasmon Resonance of Gold Nanoparticles as Colorimetric Probes for Determination of Isoniazid in Pharmacological Formulation. Spectrochim. Acta, Part A. 2013, 106, 185-189.

(3) Liu, J. M.; Wang, X. X.; Jiao, L.; Cui, M.L.; Lin, L.P.; Zhang, L.H.; Jiang, S.L. Ultra-Sensitive Non-Aggregation Colorimetric Sensor for Detection of Iron Based on the Signal Amplification Effect of $\mathrm{Fe}^{3+}$ Catalyzing $\mathrm{H}_{2} \mathrm{O}_{2}$ Oxidize Goldnanorods. Talanta. 2013, 116, 199-204.

(4) Hajizadeh, S.; Farhadi, K.; Forough, M.; Sabzi, R.E. Silver Nanoparticles as a Cyanide Colorimetric sensor in Aqueous Media. Anal. Methods. 2011, 3, 2599-2603.

(5) Liu, X.; Lin, Q.; Wei, T.B.; Zhang, Y.M. A Highly Selective Colorimetric Chemosensor for Detection of Nickel Ions in Aqueous Solution. New J. Chem. 2014, 38, 1418.

(6) Ke, J.; Li, X.; Shi, Y.; Zhao, Q.; Jiang, X. A Facile and Highly Sensitive Probe for Hg(II) Based on Metal-Induced Aggregation of ZnSe/ZnS Quantum Dots. Nanoscale. 2012, 4, 4996-5001. 
(7) Kim, H.; Na, Y.J.; Song, E.J.; Kim, K.B.; Bae, L.M.; Kim, C. A Single Colorimetric Sensor for Multiple Target Ions: the Simultaneous Detection of $\mathrm{Fe}^{2+}$ and $\mathrm{Cu}^{2+}$ in Aqueous Media. RSC Adv. 2014, 4, 22463-22469.

(8) Cate, D.M.; Dungchai, W.; Cunningham, J.C.; Volckens, J.; Henry, C.S. Simple, Distance-Based Measurement for Paper Analytical Devices. Lab Chip. 2013, 13, 2397.

(9) Xu, L.Q.; Neoh, K.G.; Kang, E.T.; Fu, G.D. Rhodamine Derivative-Modified Filter Papers for Colorimetric and Fluorescent Detection of $\mathrm{Hg} 2+$ in Aqueous Media. J. Mater. Chem. A. 2013, 1, 2526.

(10) Manori Jayawardanea, B.; Cooa, L.; Cattralla, R.W.; Kolev, S.D. The Use of a Polymer Inclusion Membrane in a Paper-Based Sensor for the Selective Determination of Cu (II). Anal. Chim. Acta. 2013, $803,106-112$.

(11) Hajizadeh, S.; Farhadi, K.; Forough, M.; Sabzi, R.E. Silver Nanoparticles as a Cyanide Colorimetric Sensor in Aqueous Media. Anal. Methods. 2011, 3, 2599-2603.

(12) Tseng, P.J.; Wang, C.Y.; Huang, T.Y.; Chuang, Y.Y.; Fu, S.F.; Lin, Y.W. A Facile Colorimetric Assay for Determination of Salicylic Acid in Tobacco Leaves Using Titanium Dioxide Nanoparticles. Anal. Methods. 2014, 6, 1759-1765.

(13) Cate, D.M.; Dungchai, W.; Cunningham, J.C.; Volckens, J.; Henry, C.S. Simple, Distance-Based Measurement for Paper Analytical Devices. Lab Chip. 2013, 13, 2397-2404.

(14) Xu, M.; Bunes, B.R.; Zang, L. Paper-Based Vapor Detection of Hydrogen Peroxide: Colorimetric Sensing with Tunable Interface. ACS Appl. Mater. Interfaces. 2011, 3, 642-647.

(15) Zargar, B.; Hatamie, A. Colorimetric Determination of Resorcinol Based on Localized Surface Plasmon Resonance of Silver Nanoparticles. Analyst. 2012, 137, 5334-5338. 
(16) Hua, C.; Zhang, W.H.; Almeida, S.R.; Ciampi, S.; Gloria, D.; Liu, G.; Harper, J.B.; Gooding, J.J. A Novel Route to Copper (II) Detection Using 'Click' Chemistry-Induced Aggregation of Gold Nanoparticles. Analyst. 2012, 137, 82-86.

(17) Zietz, B.P.; Dieter, H.H.; Lakomek, M.; Schneider, H.; Keßler- Gaedtke, B.; Dunkelberg, H. Epidemiological Investigations on Chronic Copper Toxicity to Children Exposed via the Public Drinking Water Supply. Sci. Total Environ. 2003, 302, 127-144.

(18) Barnham, K.J.; Masters, C.L.; Bush, A.I. Neurodegenerative Diseases and Oxidative Stress. Nat. Rev. Drug Discovery. 2004, 3, 205-214.

(19) Liu, X.; Zong, C.; Lu, L. Fluorescent Silver Nanoclusters for User-Friendly Detection of $\mathrm{Cu}^{2+}$ on a Paper Platform. Analyst. 2012, 137, 2406.

(20) Rice, K.P.; Walker, E.J.; Jr.; Stoykovich, M.P.; Saunders, A.E. Solvent-Dependent Surface Plasmon Response and Oxidation of Copper Nanocrystals. J. Phys. Chem. C. 2011, 115, 1793-1799.

(21) Ratnarathorn, N.; Chailapakul, O.; Henry, C.S.; Dungcha, W.; Simple Silver Nanoparticle Colorimetric Sensing for Copper by Paper-Based Devices. Talanta. 2012, 99, 552-557.

(22) Lin, Q.; Chen, P.; Liu, J.; Fu, Y.P.; Zhang, Y.M.; Wei, T.B. Colorimetric Chemosensor and Test Kit for Detection Copper(II) Cations in Aqueous Solution with Specific Selectivity and High Sensitivity. Dyes Pigm. 2013, 98, 100-105.

(23) Kazeminezhad, I.; Sadollahkhani, A. Photocatalytic Degradation of Eriochrome black-T Dye Using ZnO Nanoparticles. Mater. Lett 2014, 120, 267-270.

(24) Kanmani, S.S.; Ramachandran, K. Synthesis and Characterization of $\mathrm{TiO} 2 / \mathrm{ZnO}$ Core/Shell Nanomaterials for Solar Cell Applications. Renewable Energy 2012, 43, 149-156. 
(25) Fan, J.D.; Fábrega, C.; Zamani, R.; Shavel, A.; Güell, F.; Carrete, A.; Andreu, T.; López, A.M.; Morante, J.R.; Arbiol, J.; Cabot, A. Solution-Qrowth and Optoelectronic Properties of ZnO:Cl@ZnS Core-Shell Nanowires with Tunable Shell Thickness. J. Alloys Compd. 2013, 555, 213.

(26) Ahn, B.H.; Lee, J.Y. Effects of a Low-Temperature Sulfidation Process on the Microstructural Properties of ZnO Nanowires: ZnS Formation and Nanoscale Kirkendall Effect. CrystEngComm 2013, $15,6709-6714$.

(27) Nam, W.H.; Lim, Y.S.; Seo, W.S.; Cho, H.K.; Lee, J.Y.; Control of the Shell Structure of ZnOZnS Core-Shell Structure. J. Nanopart. Res 2011, 13, 5825-5831.

(28) Sharma, S.; Chawla, S. Enhanced UV Emission in ZnO/ZnS Core Shell Nanoparticles Prepared by Epitaxial Growth in Solution. Electron. Mater. Lett. 2013, 9, 267-271.

(29) Liu, S.; Wang, X.; Zhao, W.; Wang, K.; Sang, H.X.; He, Z. Synthesis, Characterization and Enhanced Photocatalytic Performance of $\mathrm{Ag}_{2} \mathrm{~S}-$ Coupled $\mathrm{ZnO} / \mathrm{ZnS}$ Core/Shell Nanorods. J. Alloys Compd. 2013, 568, 84-91.

(30) Wenjiang, L.; Ge, S.; Fei, X.; Minfang, C.; Yue, Z. Preparation of Spherical ZnO/ZnS Core/Shell Particles and the Photocatalytic Activity for Methyl Orange. Mater. Lett. 2013, 96, 221-223.

(31) Yuan, X.; Chen, Y. Visual Determination of $\mathrm{Cu}_{2+}$ through Copper-Catalysed in situ Formation of Ag Nanoparticles. Analyst 2012, 137, 4516-4523.

(32) Kuo, C.T.; Liu, Y.M.; Wu, S.H.; Lin, C.H.; Lin, C.M.; Chen, C.H. Visual Semiquantification via the Formation of Phase Segregation. Anal. Chem. 2011, 83, 3765-3769.

(33) Lutfullah.; Sharm, S.; Rahman, N.; Hejaz Azmi, S.N.; Iqbal, B.; Bait Amburk, M.I.B.; Al Barwanib, Z.M. UV Spectrophotometric Determination of $\mathrm{Cu}(\mathrm{II})$ in Synthetic Mixture and Water Samples. J. Chin. Chem. Soc. 2010, 57, 622-631. 
(34) Zhou, Y.; Wang, S.; Zhang, K.; Jiang, X. Visual Detection of Copper (II) by Azide- and AlkyneFunctionalized Gold Nanoparticles Using Click Chemistry. Angew. Chem., Int. Ed. 2008, 47, 74547456.

(35) Chandrasekhar, V.; Das, S.; Yadav, R.; Hossain, S.; Parihar, R.; Subramaniam, G.; Sen, P. Novel Chemosensor for the Visual Detection of Copper(II) in Aqueous Solution at the ppm Level. Inorg. Chem. 2012, 51(16), 8664-8666.

(36) Wang, Z.; Wang, M.; Wu, G.; Wu, D.; Wu, A. . Colorimetric Detection of Copper and Efficient Removal of Heavy Metal Ions from Water by Diamine-Functionalized SBA-15. Dalton Trans. 2014, $43,8461-8468$.

(37) Rodrigues, A.; Brito, A.; Janknecht, P.; Fernanda Proença, M.F.; Nogueira, R. Quantification of Humic Acids in Surface Water: Effects of Divalent Cations, pH, and Filtration. J. Environ. Monit. 2009, 11, 377-382.

(38) Kostic, I.; Andelkovic, T.; Nikolic, R.; Bojic, A.; Purenovic, M.; Blagojevic, S.; Andelkovic, D. Copper(II) and lead(II) Complexation by Humic Acid and Humic-Like Ligands, J. Serb. Chem. Soc. 2011, 76 (9), 1325-1336 .

(39) Senapati, U.S.; Jha, D.K.; Sarkar, D. Green Synthesis and Characterization of ZnS Nanoparticles. Res. J. Physical Sci. 2013, 1, 1-6.

(40) Shuai, X.M.; Shen, W.Z. A Facile Chemical Conversion Synthesis of ZnO/ZnS Core/Shell Nanorods and Diverse Metal Sulfide Nanotubes. J. Phys. Chem. C 2011, 115, 6415-6422.

(41) Zhu, Y.F.; Fan, D.H.; Shen, W.Z. A General Chemical Conversion Route to Synthesize Various ZnO-Based Core/Shell Structures. J. Phys. Chem. C 2008, 112, 10402-10406.

(42) Lubeck, C.R.; Han, T.Y.; Gash, A.E.; Satcher, J.H.; Jr.; Doyle, F.M. Synthesis of Mesostructured Copper Sulfide by Cation Exchange and Liquid-Crystal Templating. Adv. Mater. 2006, 18, 781-784 
Table 1: Comparison of the results of the present sensor with some other published papers for $\mathrm{Cu}^{2+}$ ion detection.

\begin{tabular}{cccc}
\hline Analytical technique & LDR $(\boldsymbol{\mu M})$ & LOD $(\boldsymbol{\mu M})$ & Reference \\
\hline Proposed method & $15-1500$ & $15^{\mathrm{c}}$ & This work \\
Colorimetric method: Paper sensor & $7.8-62.8$ & Not reported & 21 \\
Colorimetric method: test kit & Not reported & 0.1 & 22 \\
Spectrophotometry & $15.9-126.0$ & 0.4 & 33 \\
Spectrophotometry & Not reported & $>50.0$ & 34 \\
Spectrophotometry & Not reported & $20^{\mathrm{c}}$ & 35 \\
Spectrophotometry & Not reported & $14.9^{\mathrm{c}}$ & 36 \\
\hline
\end{tabular}

LDR: Linear dynamic range

LOD: limit of ditection 
Table 2: Determination of $\mathrm{Cu}^{2+}$ in a river water sample by a standard addition method.

\begin{tabular}{cccc}
\hline Add $\mathrm{Cu}^{2+}(\boldsymbol{\mu M})$ & Found $\mathrm{Cu}^{2+}(\boldsymbol{\mu M})$ & Recovery (\%) & Relative error $(\%)$ \\
\hline 0 & 0 & 94.6 & - \\
75 & 71 & 96.6 & 3 \\
300 & 290 & 96.0 & 4 \\
\hline
\end{tabular}




\section{Figure and table captions}

Figure 1: a) XRD spectrum, b) TEM image, c) ATR-FTIR spectrum, and d) SEM image of ZnO@ZnS CSNPs

Figure 2: a) Column plot of the colour intensity versus time, and b) changes of the filter paper every 5 $\min$.

Figure 3: a) The column plot of colour intensity at different $\mathrm{pH}$, and b) the column plot of colour intensity for different buffer concentrations.

Figure 4: (a) The color intensity versus the $\mathrm{Cu}^{2+}$ ions concentration obtained by the ImageJ with a digital photograph as an inset, (b) the value of the color intensity versus the $\mathrm{Cu}^{2+}$ ions concentration, and (c) the calibration curve of the color intensity at different concentrations of the $\mathrm{Cu}^{2+}$ ions.

Figure 5: Selectivity of the paper sensor with different cations and anions.

Figure 6: The column plot of the colour intensity for the real and the experimental samples.

Figure 7: Sensitivity of the paper sensor based on the $\mathrm{ZnS}$ NPs for different $\mathrm{Cu}^{2+}$ ions concentrations.

Figure 8: XRD spectra of the paper, paper sensor, and used after adding $\mathrm{Cu}^{2+}$ ions.

Figure 9: SEM images of the paper, paper sensor, and used paper sensor after adding $\mathrm{Cu}^{2+}$ ions.

Table 1: Comparison of the results of the present sensor with some other published papers for $\mathrm{Cu}^{2+}$ ion detection.

Table 2: Determination of $\mathrm{Cu}^{2+}$ in a river water sample by a standard addition method. 

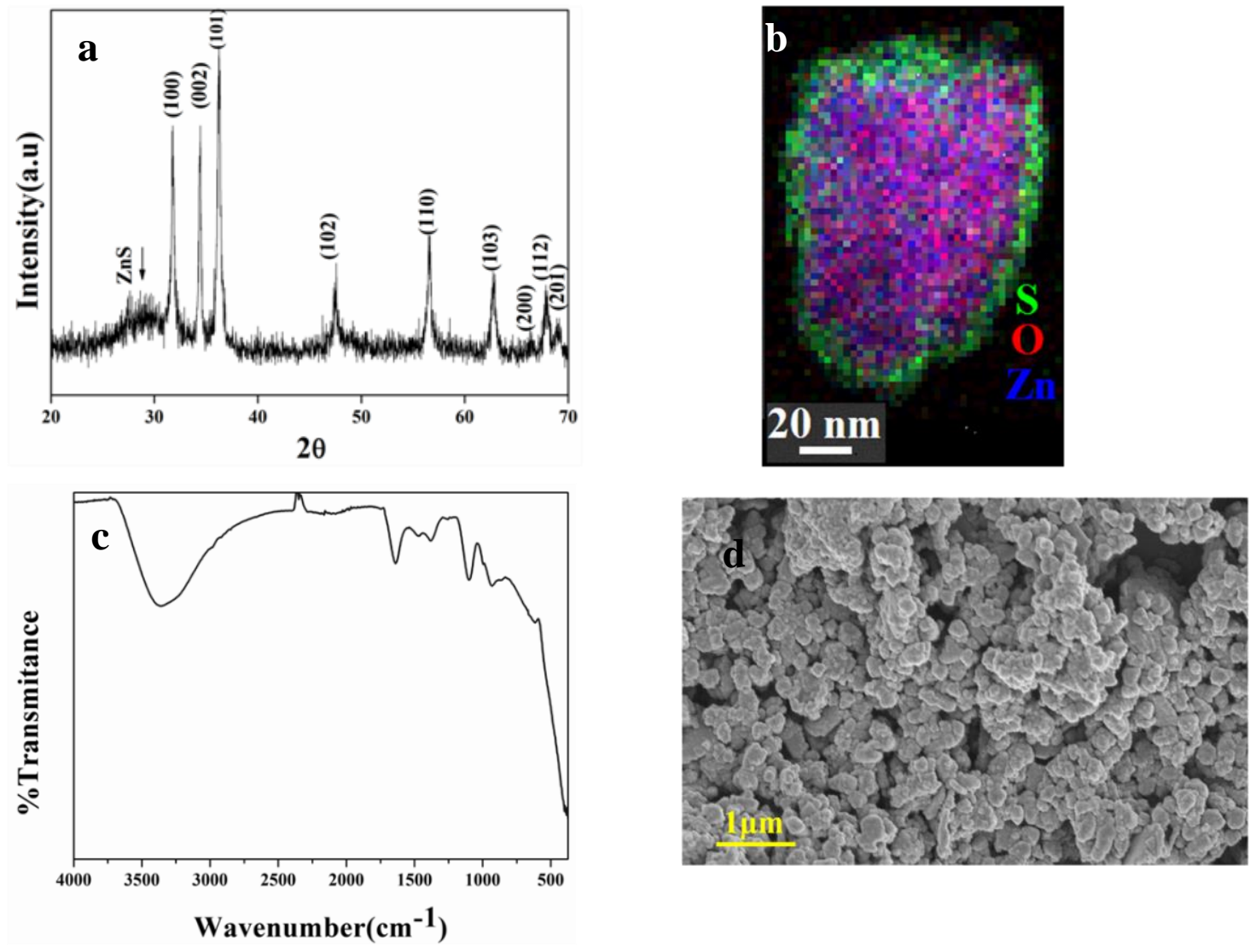

Figure 1. 

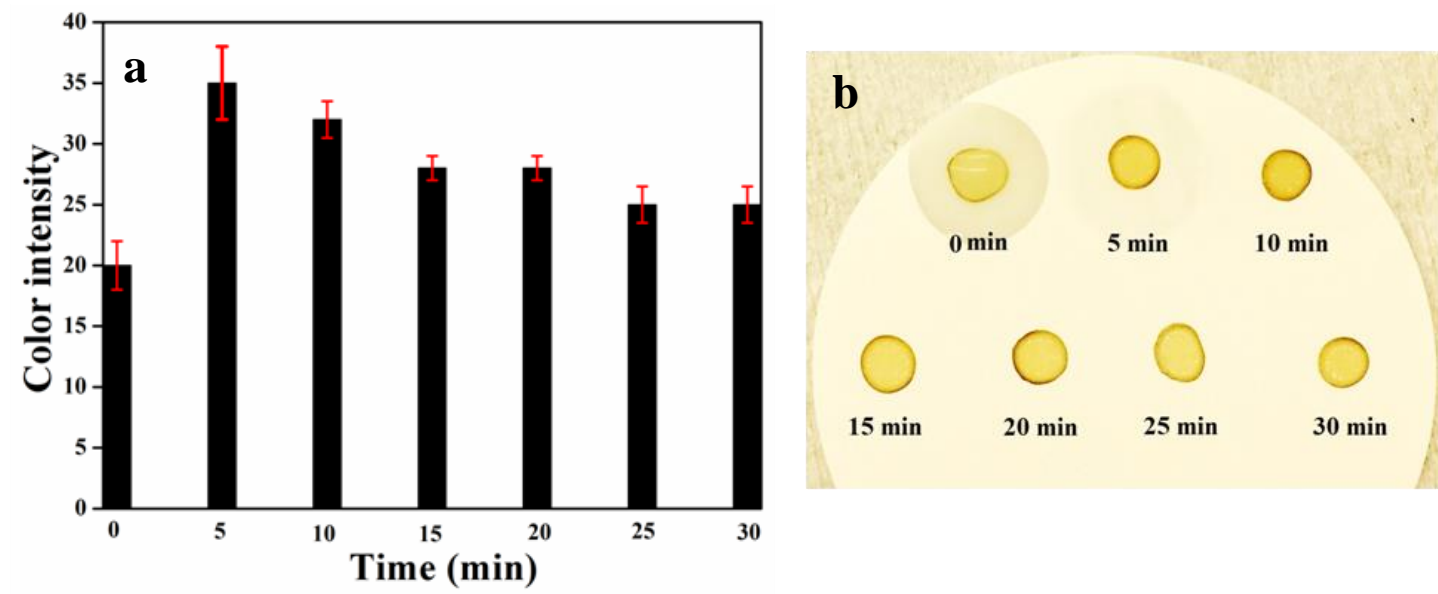

Figure 2.
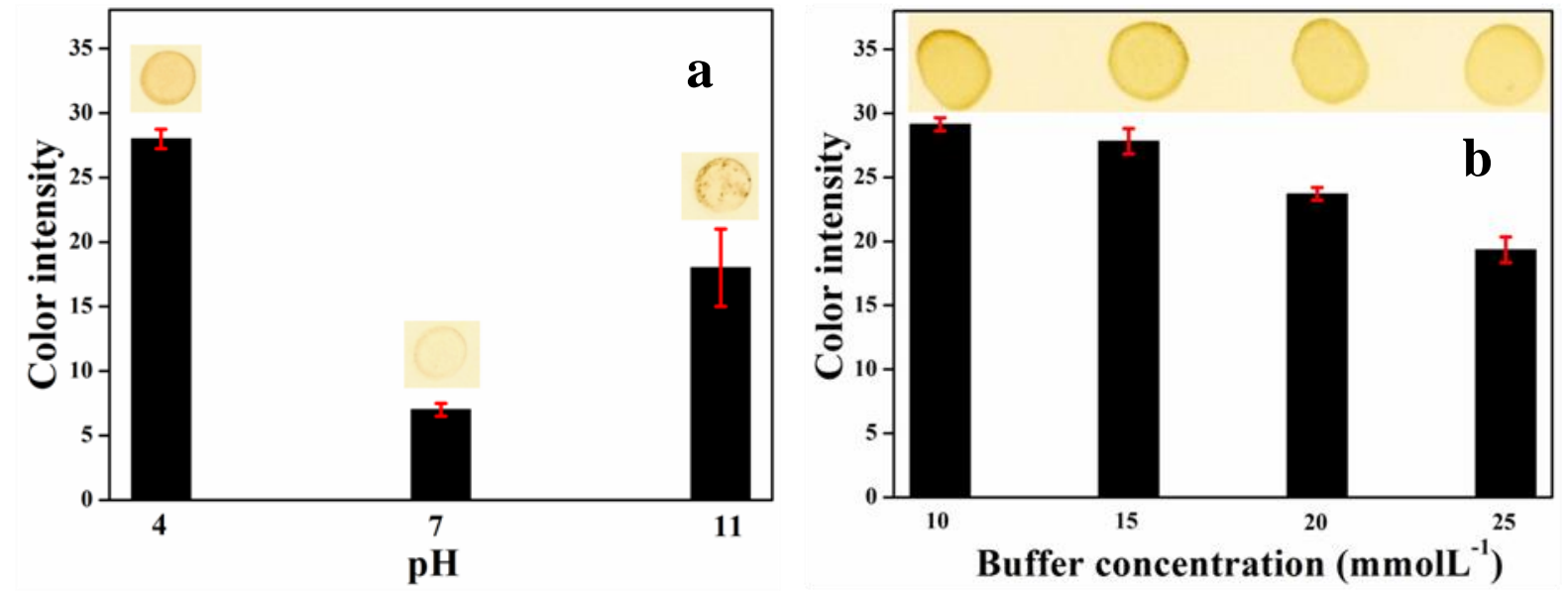

Figure 3. 

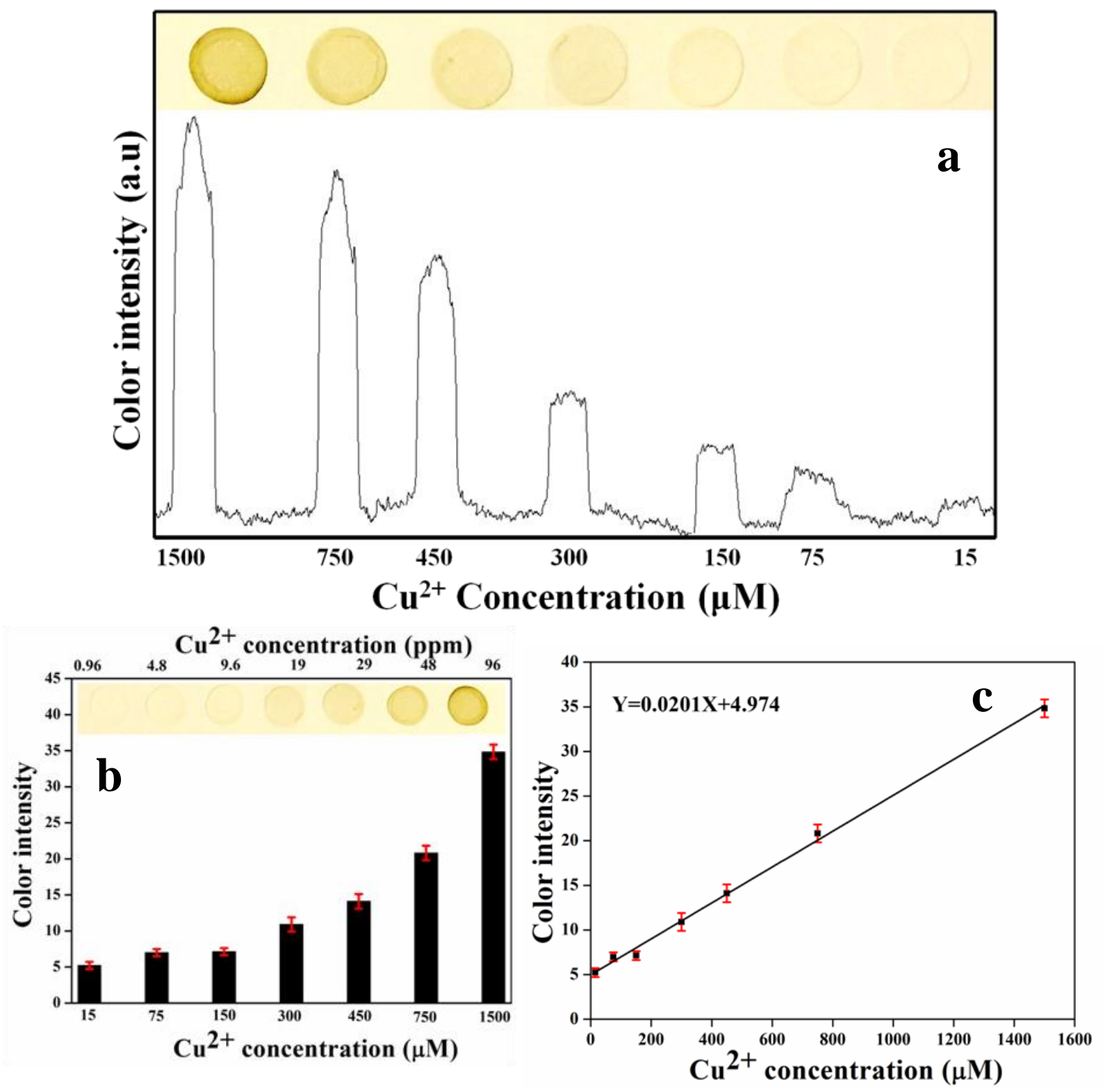

Figure 4. 


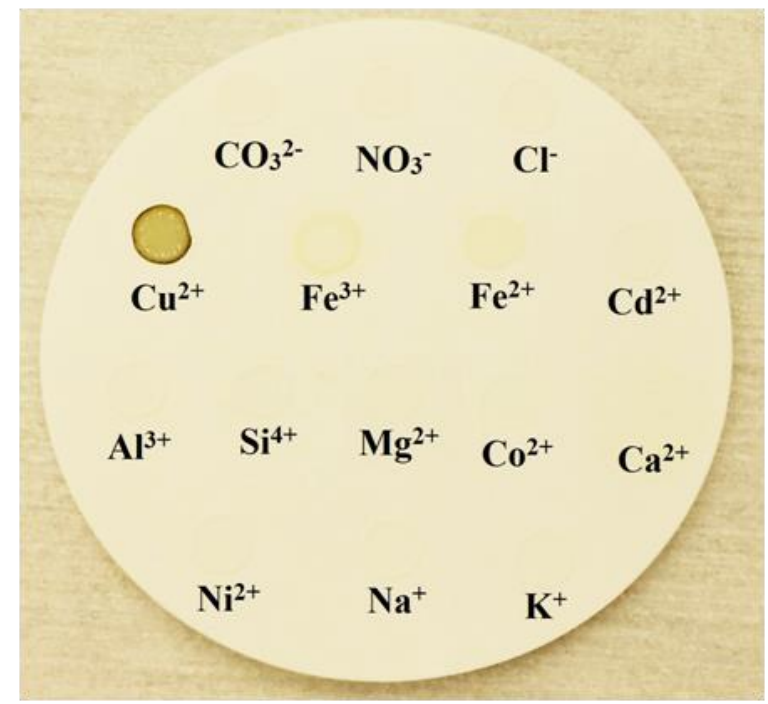

Figure 5

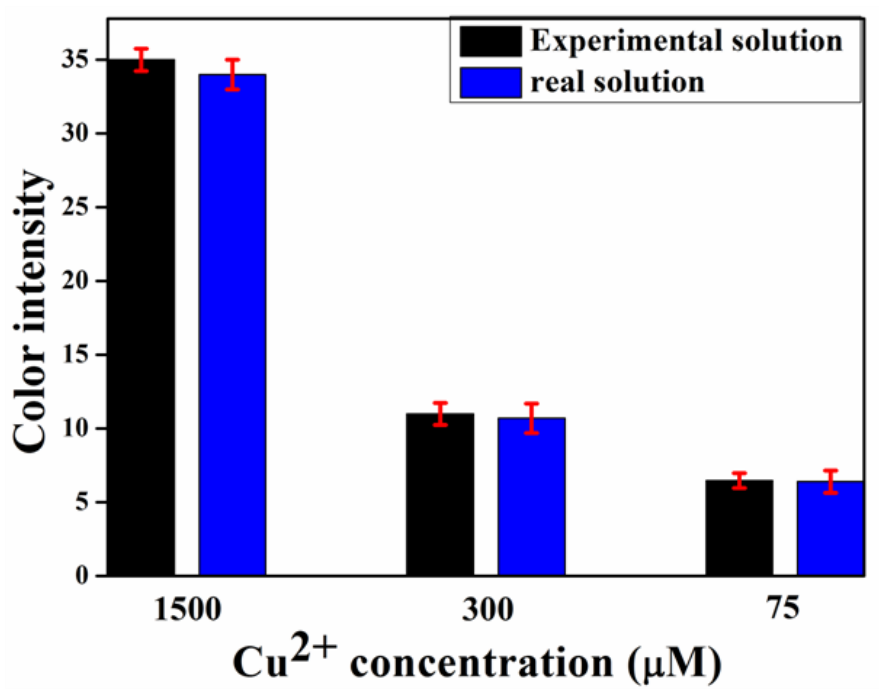

Figure 6. 


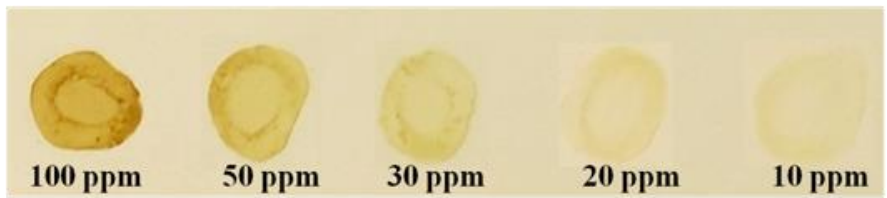

Figure 7.

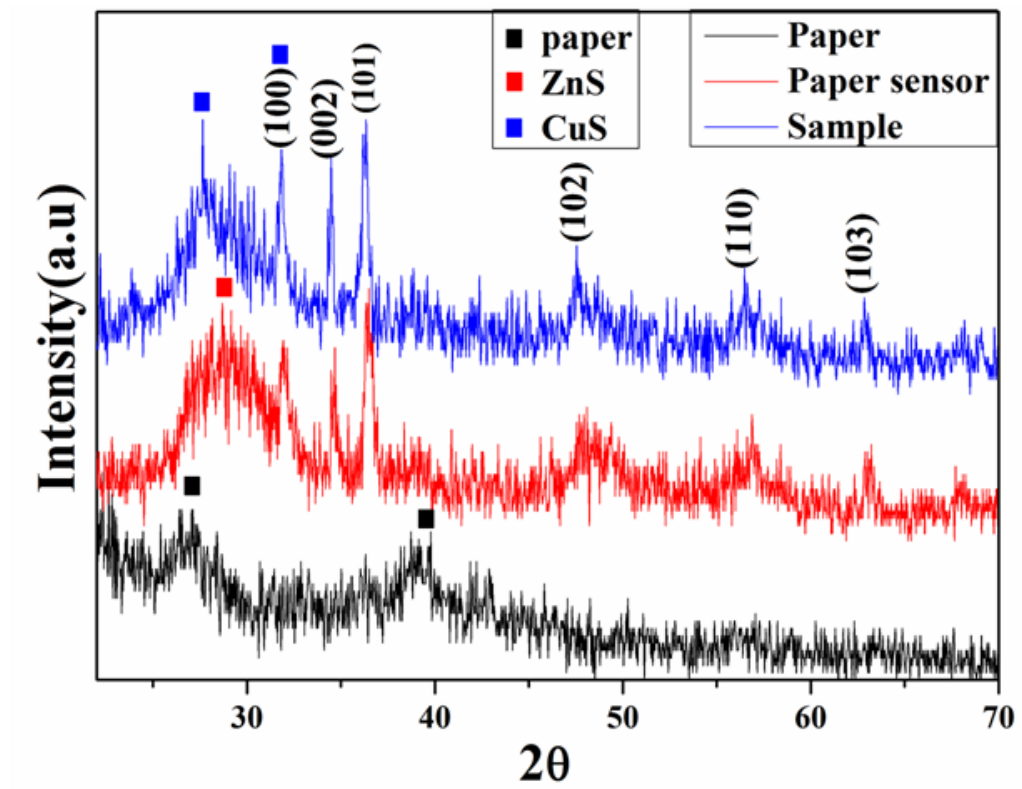

Figure 8. 

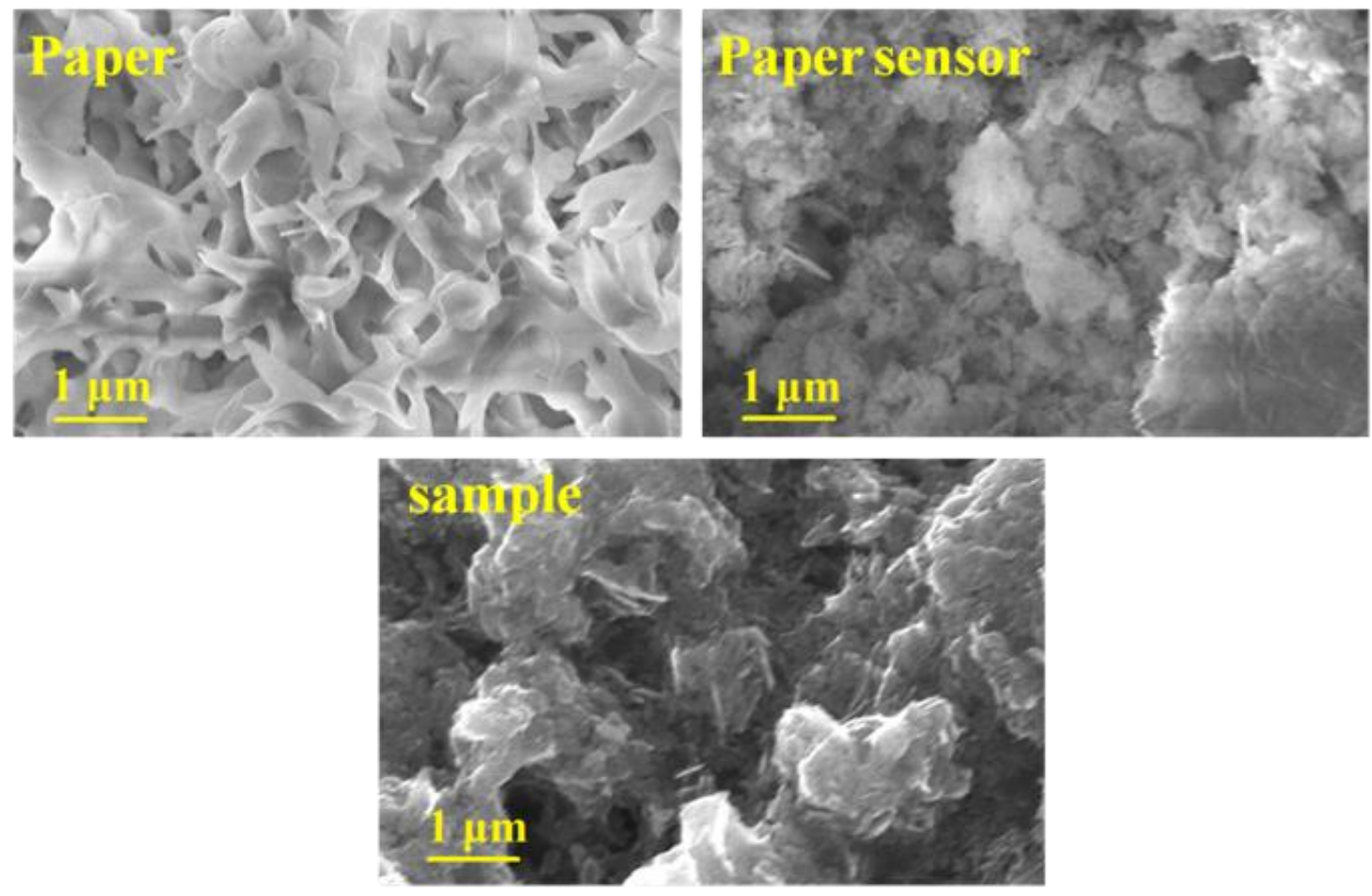

Figure 9. 